\title{
Do pequeno gesto ao monumento
}

\author{
From the Little Gesture to the Monument
}

Del pequeño gesto al monumento

Luciano Vinhosa (Universidade Federal Fluminense, Brasil) *

https://doi.org/10.22409/poiesis.v21i36.42736

RESUMO: Este memorial reflexivo traz o processo de idealização e realização da exposição Do pequeno gesto ao monumento, em exibição entre os dias 26 de abril e 25 de maio de 2019 na Galeria do Museu Universitário de Arte (MUnA-UFU), em Uberlândia, estado de Minas Gerais. Na exposição apresentei dois trabalhos autônomos de minha autoria, $O$ pequeno gesto e Monumentos, feitos em épocas e por motivações muito diferentes, mas que foram postos em relação através do conceito de monumento e de seu revés, o antimonumento.

PALAVRAS-CHAVE: monumento; antimonumento; procedimentos e processos

\footnotetext{
* Luciano Vinhosa é artista e teórico, Professor Associado do Departamento de Arte e do Programa de Pós-Graduação em Estudos Contemporâneos das Artes da Universidade Federal Fluminense. Bolsista de Produtividade em Pesquisa do CNPq. E-mail: luciano.vinhosa @gmail.com. Orcid: https://orcid.org/0000-0001-8593-1223
} 
ABSTRACT: This reflective memorial brings the process of idealization and realization of the exhibition From the Little Gesture to the Monument, on display between April 26 and May 25, 2019 at the Gallery of the University Museum of Art (MUnAUFU), in Uberlândia, Minas Gerais state. On the occasion, I presented two autonomous works of my authorship, The Little Gesture and Monuments, made at different times and for very different reasons, but which were put in relation through the concept of monument and its setback, the anti-monument.

KEYWORDS: monument; anti-monument; procedures and processes

RESUMEN: Este ensayo presenta el proceso de idealización y realización de la exposición Del pequeño gesto al monumento, en exhibición entre el 26 de abril y el 25 de mayo de 2019 en la Galería del Museo de Arte de la Universidad (MUnAUFU), en Uberlândia, estado de Minas Gerais. En la ocasión, presenté dos obras autónomas, El pequeño gesto y Monumentos, realizadas en diferentes momentos y por razones muy diferentes, pero que estaban vinculadas a través del concepto de monumento y su revés, el anti-monumento.

PALABRAS CLAVE: monumento; anti-monumento; procedimientos y procesos

Citação recomendada:

VINHOSA, Luciano. Do pequeno gesto ao monumento. Revista Poiésis, Niterói, v. 21, n. 36, p. 83-106, jul./dez. 2020. [https://doi.org/10.22409/poiesis.v21i36.42736]

(cc) BY-NC-ND Este documento é distribuído nos termos da licença Creative Commons Atribuição-NãoComercial 4.0 Internacional (CC-BY-NC) (c) 2020 Luciano Vinhosa

Luciano Vinhosa, Do pequeno gesto ao monumento. 


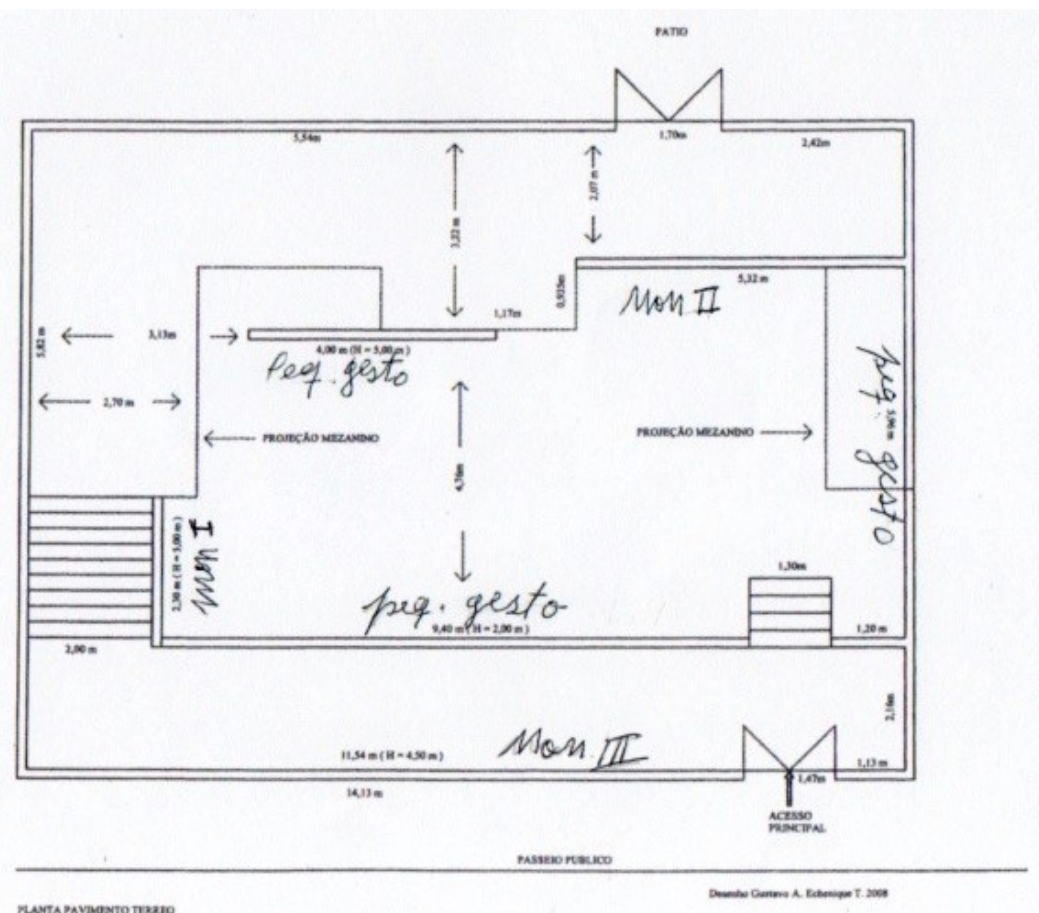

Fig. 1 - Projeto expográfico da mostra Do pequeno gesto ao monumento, individual de Luciano Vinhosa na Galeria do Museu Universitário de Arte (MUnA-UFU), em Uberlândia, estado de Minas Gerais (abril-maio de 2019)

(nas páginas seguintes, imagens com vistas parciais da exposição) 


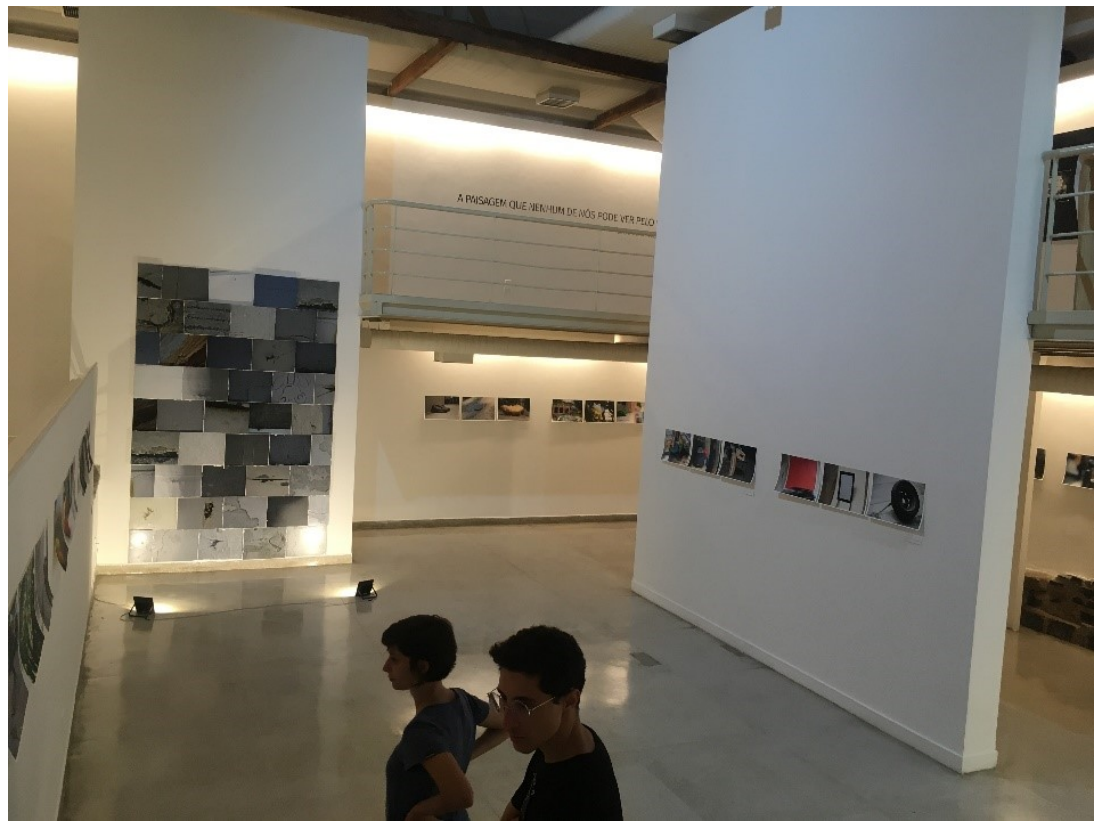




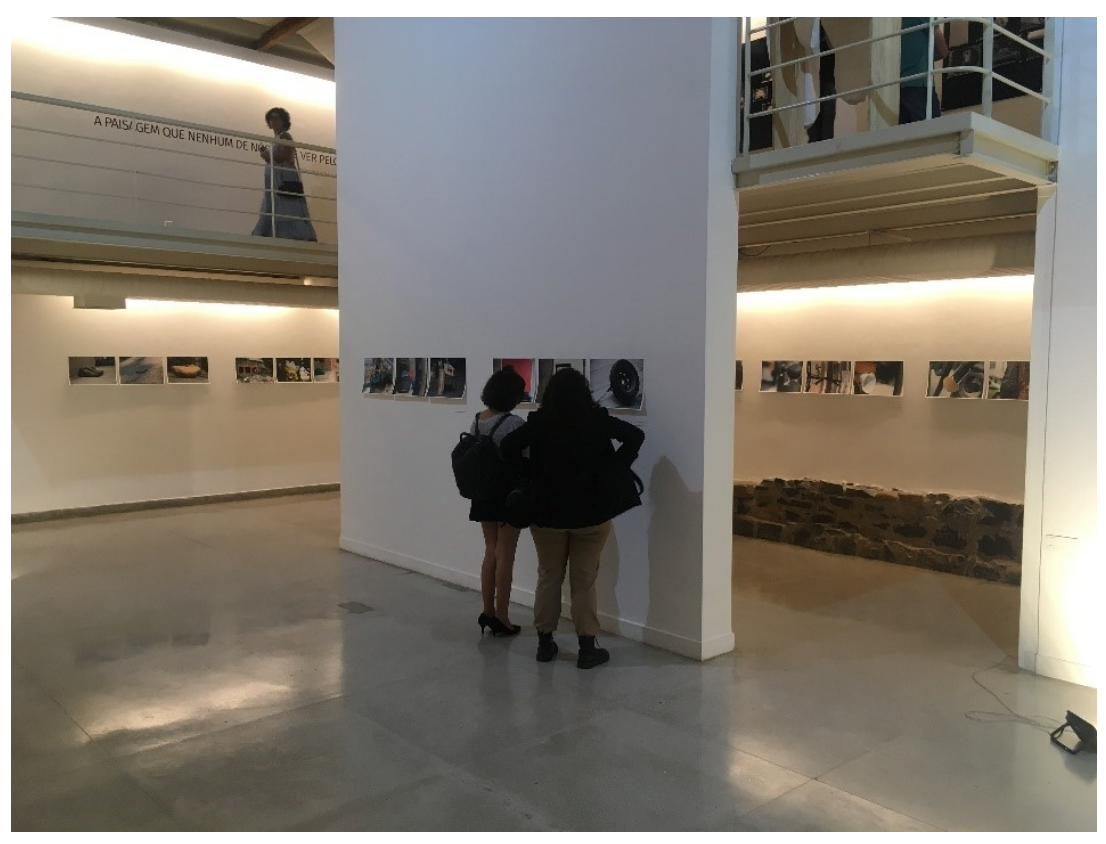




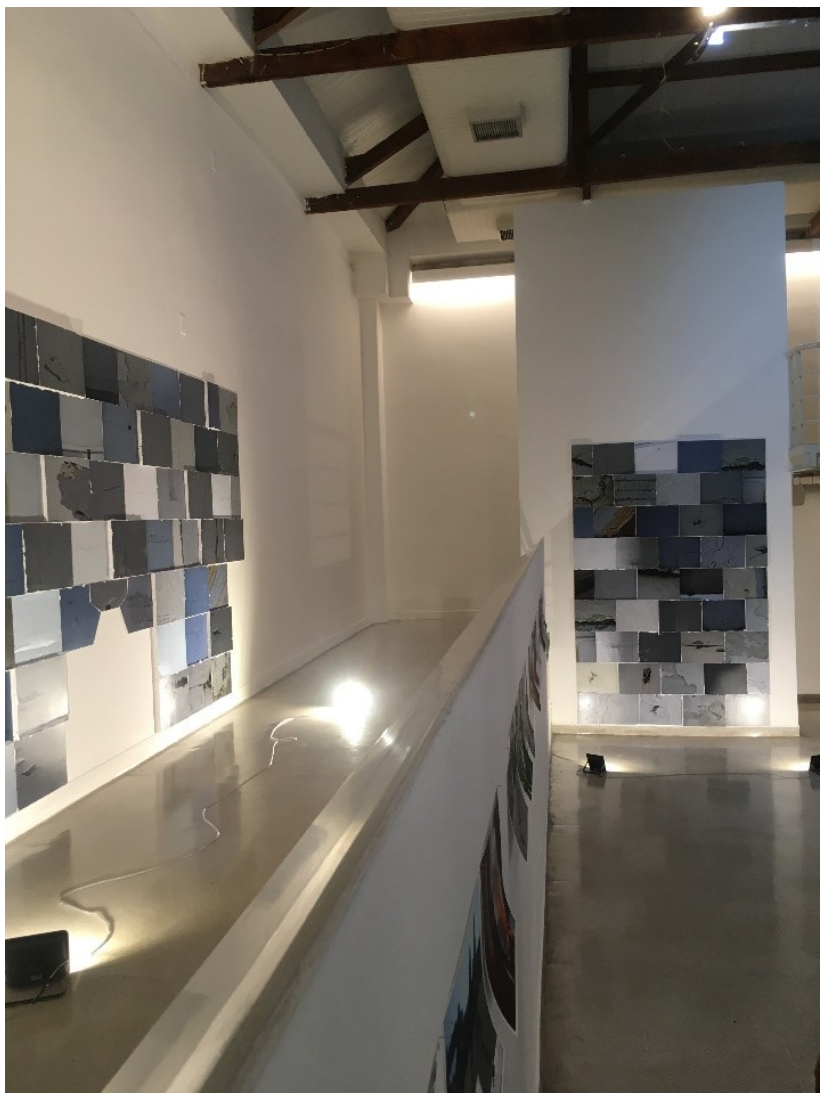



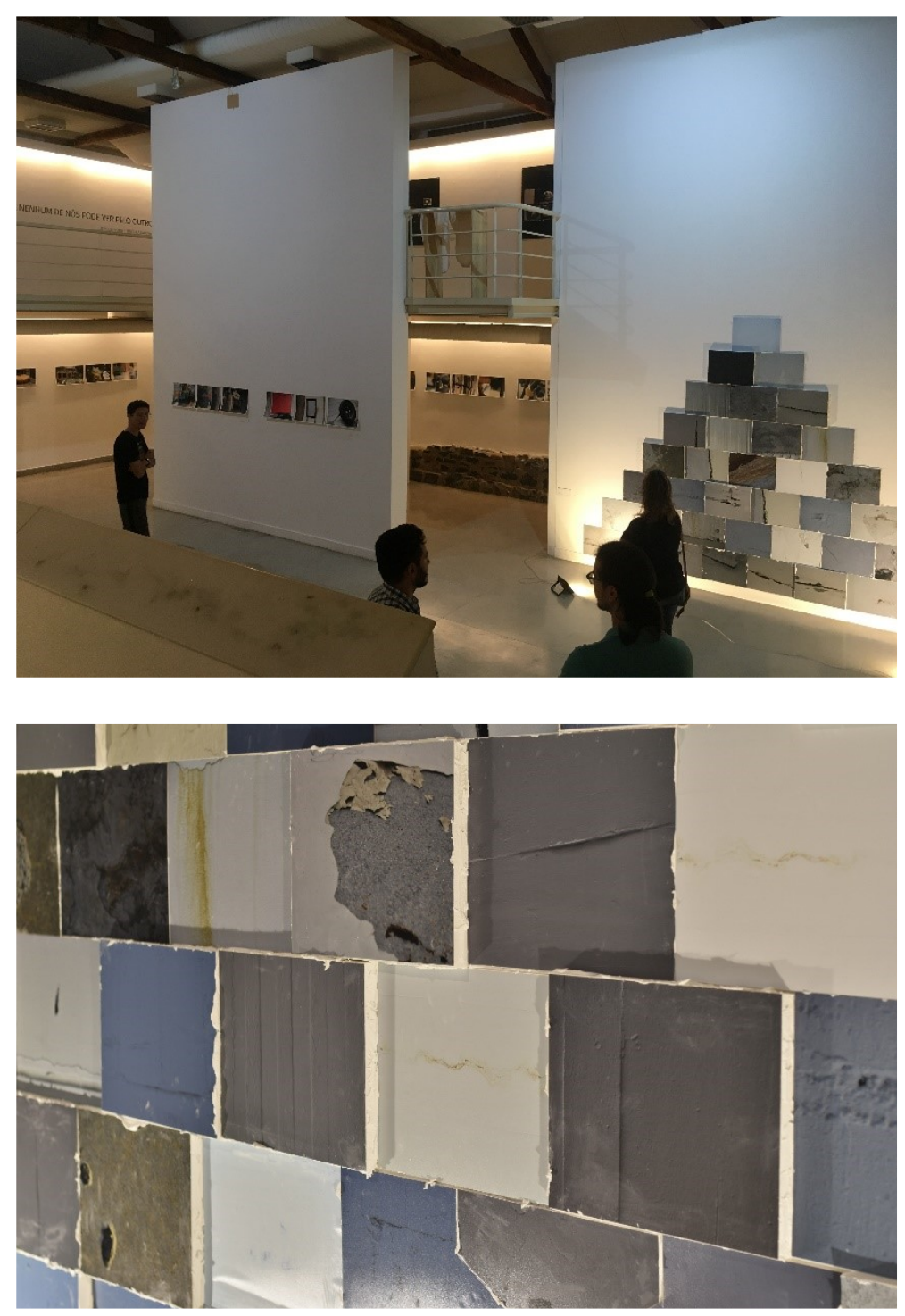

Revista Poiésis, Niterói, v. 21, n. 36, p. 83-106, jul./dez. 2020. (https://doi.org/10.22409/poiesis.v21i36.42736) 


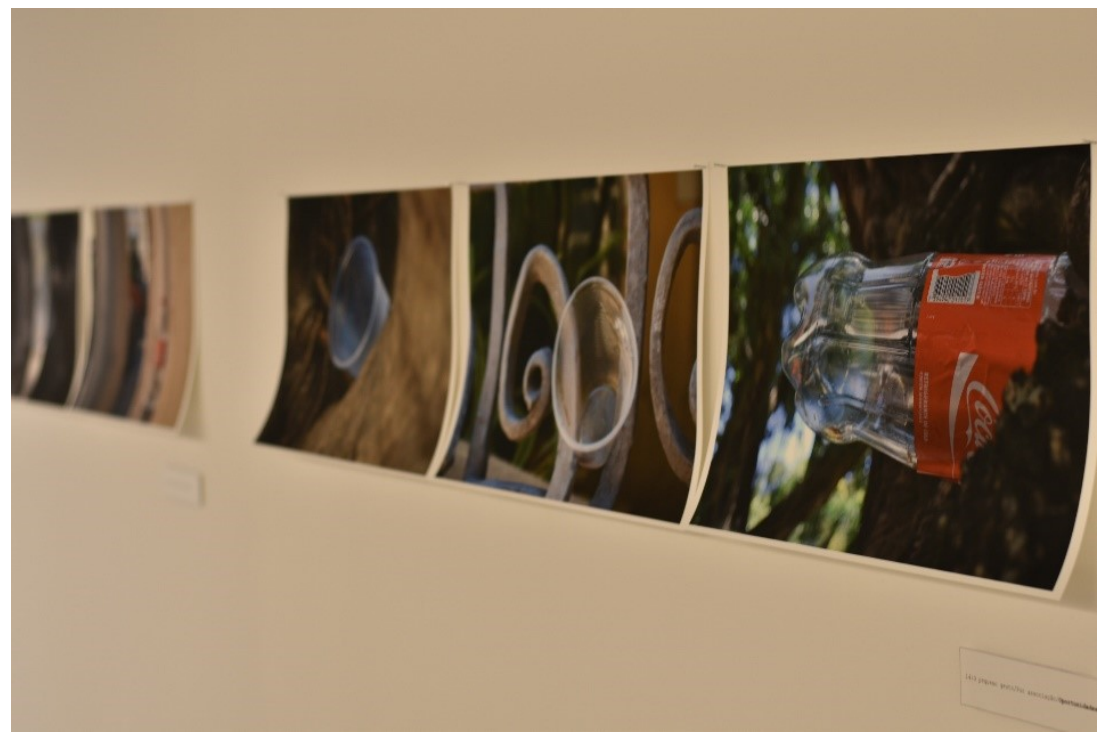




\section{Do pequeno gesto ao monumento}

\section{Alguns prolegômenos}

Entre os anos de 2012 e 2013, desenvolvi a pesquisa $O$ pequeno gesto, dois ensaios em torno da experiência ordinária, como parte integrante de minhas investigações de pós-doutorado desenvolvidas na França, com supervisão do Professor JeanPierre Cometti. Essa iniciativa teve como ponto de partida dois pressupostos teóricos: 1) a experiência estética é toda e qualquer experiência de entrega irrestrita de nossos sentidos em interação com o mundo exterior, mas ganha espessura e profundidade na medida em que a vivemos intensamente e de tal forma integrada em nosso corpo operante, que ela passa definitivamente a fazer parte de nossa subjetividade constitutiva; ${ }^{1}$ 2) O "fazer" é um modo particular de organizarmos a experiência comum a partir da instauração de procedimentos que, ao fim e ao cabo, 
Ihe atribuem forma artística, ainda que provisória. Portanto, pressupõe objetivação operacional de um método fazendo-se ou de trabalho em ação, viabilizado por atividade mental e programática em integração com a performatividade corporal do sujeito, o que chamamos de processo visando o objeto. Nesse sentido, difere-se do modo analítico e conceitual de como a linguagem representa as ideias. Assim, se a primeira colocação eu pude responder filosoficamente; a segunda só foi possível com a realização de um trabalho artístico.

Cabe aqui relativizar a noção de trabalho e, concomitantemente, de seu derivado, o objeto artístico. Obviamente, quando falamos de objeto queremos dizer simplesmente tudo aquilo que, tendo origem no sujeito, é passível de circular no mundo exterior, ser compartilhado e, de algum modo, abandoná-lo quando reproduzido por terceiros, ainda que se trate de instância imaterial, por exemplo, um simples discurso ou uma performance. Por outro lado, a própria noção de trabalho remete a uma atividade ou, como nos referimos acima, ao trabalho em ação e não ao objeto que ele gera. A esse título, Delfin Sardo (2017), ao refletir sobre a possibili- dade do trabalho artístico na arte contemporânea, afirma que

\section{[...] a noção de trabalho se dilui num processo de gestão de projecto, na medida em que a produ- ção, tida como a relação formal da mão sobre 0 suporte, é progressivamente substituída pela concepção da criação artística como gestação - ou mesmo gestão - de um projecto. (num senti- do muito próximo da acepção deste termo na engenharia e na arquitetura) [...] (SARD0, 2017, p. 34)}

Ainda sobre os dois pressupostos, é necessário esclarecer primeiro, em relação à experiência, que ela se dá como acontecimento singular ou evento em sua plenitude. Segundo Peirce (1978):
Nós percebemos os objetos que se acham diante de nós; mas a coisa, mediante a qual fazemos es- pecialmente a experiência - e a qual a palavra experiência mais se aplica particularmente - é um evento. Nós não percebemos os eventos [...] nós fazemos a experiência com eles sem necessa- riamente percebê-los. É o campo especial da ex- periência que nos informa sobre os eventos, so- bre as mudanças de percepção. Ora, o que carac- teriza particularmente as mudanças de percep- ção é 0 choque. [...] 0 conceito de experiência é 
mais largo que o de percepção e inclui muito mais coisas que não são, propriamente falando, objetos de percepção. (p. 93-94)

Se a ideia de choque que acompanha uma mudança súbita de percepção está no centro da definição de evento em Peirce (1978), entre esse último autor e Dewey (2006), podemos chegar a um denominador comum, e especular que, se a experiência tem um objeto pontiagudo que a desencadeia inicialmente, ela no entanto delonga-se como um processo que, sofrido em nossa subjetividade, apresenta picos e ínfimos de intensidade, tal como quando escrevo esse texto e o vivo na experiência de escrevê-lo, em tudo relacionando-a a um contexto em que estamos inseridos.

Assim que um relâmpago ilumina uma paisagem sombria, nós podemos ver momentaneamente os objetos. Mas este reconhecimento não é em si um simples ponto no tempo. Ele é o ponto focal e culminante de lentos e longos processos de maturação. Ele é a manifestação, em um instante culminante, repentino e isolado, da continuidade de uma experiência temporal ordenada. Se considerado à parte, seria tão insignificante como seria a tragédia de Hamlet se ela estivesse limitada a um único verso ou a uma única palavra isolada de todo 0 contexto. (DEWEY, 2016, p. 45) $)^{3}$

Portanto, se estamos acompanhando devidamente os autores, ainda que desencadeada por um choque inicial que induz nossos sentidos a uma atenção súbita ao mundo exterior, a experiência na qual estou envolvido implica um processo complexo que me faz associar o objeto de minha percepção a uma superposição de tempos, de evocações de estados emocionais, de experiências passadas e de inúmeras outras relações em curso no ato de sua subjetivação. Então, essa experiência integra momentos superpostos de ação e de separ[ação] ou contemplação que, durante seu decurso, faz o trânsito permanente do informe à forma e, vice-versa, da forma ao informe, até que se estabilize ao risco de se cair na entropia.

Em segundo lugar, a noção do fazer artístico implica em criar procedimentos e regras, portanto, trabalho em ação, cujos fins estão na satisfação em concluí-las ao risco de se criar um eterno objeto ansioso. Nesse ponto, trabalho em ação e evento nivelam-se na justa medida em que são solidários com a emergência da experiên- 
cia integralmente vivida em nosso corpo e, de algum modo, completa porque sofrida em nossa subjetividade.

\section{0 pequeno gesto, ensaio em torno da experiência ordinária}

O pequeno gesto nasce, primeiramente, de uma relação íntima e cotidiana que mantenho com o meio urbano desde minhas caminhadas solitárias em paisagens edificadas, as mais variadas, as quais guardam em si traços remarcáveis de ações humanas. ${ }^{4}$ Assim, pelas diferente cidades por onde pude passar, estive atento às formas de descarte de certos objetos. Chamou-me a atenção, por um lado, o modo recorrente e universal como esse desembaraço é feito, obedecendo a certa relação sistêmica recorrente entre objeto descartado e componentes delineadores do espaço de uso comum, seja enfiando-o em frestas de muros que separam os domínios públicos e privados, entre troncos de árvores que se alinham nos passeios públicos, seja espetando-o em lanças de grades de jardins, depositandoo em recuos de soleiras que desnivelam as passagens entre o exterior e o interior/o interior e o exterior das edificações, e muitos outros modos de estabelecer certas "situações específicas" e, por outro lado, a lembrança que tais situações trazem do gesto do sujeito anônimo que as engendrou. Digo "situação" porque os gestos não estão isolados, estão justamente ali nos nichos naturais que a cidade, em retorno, Ihes oferece.

Existe nesses objetos desprezados e desprezíveis uma energia potencial que é também a memória de uma ação pretérita que age no momento mesmo em que os observo e, em efeito reverso, ela ativa-se no aqui e agora da experiência que realizo com eles. É um gesto diminuto e insignificante, mas definitivo, que releva algo de nossa espécie, de nossos cacoetes civilizatórios e, talvez, de uma inconsciência coletiva mais vasta. A máquina fotográfica foi a ferramenta necessária para a fixação dessa experiência tanto banal quanto insólita. Banal, porque encontramos com esses objetos todos os dias, por todo lado em que a cidade se estende e mal the dispensamos nossa atenção; insólita, porque faz relevar do ordinário a fina camada extraordinária encoberta pela rotina. Um 
efeito que somente a imagem técnica pode realizar com eficiência. A lente de aumento torna patético o diminuto e outrora insignificante gesto de desempecilho, mas que ganha trama e espessura na lembrança que trago comigo, no arquivo digital e em minha coleção de fatos, para sempre, memoráveis. Habitando em mim, o gesto morto, largado ao léu, torna-se agora, e a uma só visada, potente, para sempre inesquecível - uma IMAGEM -, tal a força vital que, ao revés, emana da fraca energia que registrei. Enamorado do banal e quase apagado na paisagem, aqui está agora o gesto potente prisioneiro da fotografia - essa morta-viva.

Fixados em imagens, passei a classificar os gestos a fim de organizar um arquivo protopoético, como as fotografias emprestaram um dia suas certezas às ciências. Sem delongar-me em detalhes de como todo o processo, desdobrando-se em procedimentos, deu consistência ao trabalho ${ }^{5}$, adiantarei que esse arquivo foi organizado da seguinte forma ${ }^{6}: 75$ fotografias, todas tomadas no formato paisagem, estão agrupadas em conjuntos de 5 imagens por tipo, perfazendo 15 grupos organizados nas seguintes entradas, aqui disposta em ordem alfabética : 1) [Ali]; 2) [Aqui]; 3) [Assim!]; 4) [Assinaladas]; 5) [Dádivas]; 6) [Do lado de cá]; 7) [Do lado de lá]; 8) [Enfiadas]; 9) [Guardadas]; 10) [Imitação da arte]; 11) [Lá]; 12) [Lançadas fora]; 13) [Lembrar!]; 14) [Oportunidades]; 15) [Parassempre]. Esse grupo de 15 categorias, por sua vez, rearranjam-se em outras 3 subcategorias mais amplas: A- [Por associação]: (5), (10), (13), (14), (15) ; B- [Por modo]: (3), (4), (8), (9), (12) ; C[Por posição]: (1), (2), (6), (7), (11).

Chamei esse arquivo de protopoético porque, referindo-se ao modo rígido de como a ciência organiza o conhecimento e a 95 qual a fotografia prestou e ainda presta grande serviço, ele a ficciona ao criar certa fluidez e transversalidade entre as imagens fixadas e os tipos, as quais podem ajustar-se simultaneamente a mais de uma categoria ou pular de uma à outra. Por outro lado, a própria insignificância do objeto abordado joga ironicamente com o despropósito e a imprecisão das ciências, igualando-as às incertezas da arte. Entre a ciência e a arte, $O$ pequeno gesto estende, então, um fino fio bem tensionado. 


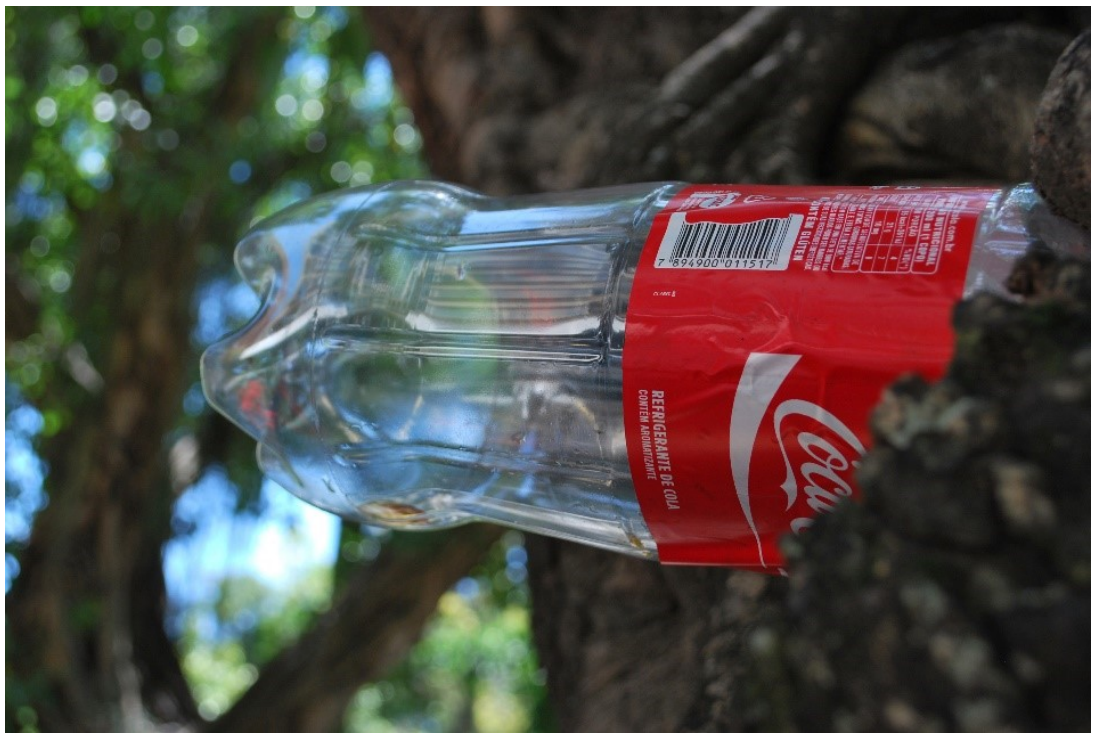

Fig. 8 - Luciano Vinhosa, O pequeno gesto, 2003.

fotografia digital (para a cópia em papel, $30 \times 45 \mathrm{~cm}$ ) 


\section{Outro monumento}

Em 2014, fui convidado pelo então diretor do Museu de Arte Contemporânea de Niterói, Luiz Guilherme Vergara, para participar, integrando o grupo de brasileiros, de uma exposição com o coletivo internacional de artistas Suspended Spaces. A convocatória instigava-nos a trabalhar a partir do Caminho Niemeyer, percurso pontuado por equipamentos culturais, criados pelo arquiteto modernista brasileiro, ao longo da orla da baía de Guanabara, em Niterói.

O Caminho, iniciando-se no complexo da Praça Popular, região central, segue até o terminal hidroviário, no bairro de Charitas. O Museu de Arte Contemporânea, ícone emblemático da cidade, constitui, por sua graciosa elegância e situação privilegiada, o ponto culminante do percurso.

O título da exposição, Espaços Deslocados - Futuros Suspensos, apontava para o conceito curatorial, em si, bastante sugestivo de um projeto sempre malogrado. No contexto de um país periférico, a arquitetura futurista do arquiteto socialista parece-nos desde sempre deslocada, para não dizer despropositada, em meio a tantas demandas sociais que podem ser notadas a olhos nus em todos os arredores da cidade, até aonde a vista alcança. As formas limpas e esculturais de suas edificações sugerem objetos a serem apreciados de longe. $E$, neste sentido, são muito eficazes no que tange aos interesses turísticos e culturais de uma cidade que carecia até então de monumentos marcantes que pudessem competir em força de igualdade com os de sua vizinha, a Cidade MaraviIhosa. Fosse essa uma iniciativa dos políticos para chamar atenção para si mesmos como grandes realizadores de obras públicas, ela é também o sintoma da ineficácia desses mesmos homens em enfrentar com coragem os problemas que, de fato, afligem-nos e impedem-nos de termos ao alcance das mãos o futuro que sonhamos.

No primeiro encontro com o coletivo Suspended Spaces e a direção do museu, ficou combinada uma visita de reconhecimento que, começando pela Praça Popular, seguiria por toda orla por onde se estende o Caminho Niemeyer. Era mês de agosto, inverno ainda no Sul, mas com um calor já escaldante e uma luz muito intensa e dura. A Praça Popular é, de fato, um conjunto composto por três prédios O Memorial Roberto Silveira, o Teatro Po- 
pular e o Museu da Ciência e da Criatividade - instalados sobre uma superfície plana, cimentada e vazia, sem nenhuma vegetação robusta que possa competir em atenção com as atrações propriamente ditas: as formas entrelaçadas e sensuais do conjunto, tão características da arquitetura de Oscar Niemeyer. A visita ocorreu por volta do meio-dia. Nesta hora, sob o sol causticante, o vento morno varria a esplanada. Nenhuma presença humana, apenas uma matilha de cães vira-latas errava na planície desolada, eventualmente procurando abrigo nas sombras das rampas que ornam e dão acesso aos prédios.

Aquilo que de longe acolhe o olhar por sua leveza e limpidez, de perto revela-se hostil e pouco amistoso à vida. A Praça Popular surpreende-nos pelo caráter monumental e tanto mais melancólico das ruínas de um futuro sempre interrompido. Há algum tempo eu vinha refletindo sobre a condição do monumento e de sua clareza formal: frontalidade, elevação vertical e planar, assentamento gravitacional de suas massas sobre a terra, a imposição de sua presença sobre o corpo do sujeito, sua origem fúnebre e ritualística, o silêncio cerimonial que o envolve, a vulnerabilidade da condição humana que evoca, entre outros aspectos. $O$ encontro com a arquitetura de Niemeyer foi então a ocasião propícia para pôr em prática minhas elucubrações teóricas e experimentar. Vindo de uma prática da escultura, mais recentemente passei a trabalhar com a fotografia. Pensar o monumento através da fotografia foi a oportunidade de tratá-la não como imagem, mas como matéria integrando o corpo escultural.

Sobre os volumes brancos e insuspeitos de Niemeyer, chamou-me a atenção as cicatrizes do tempo, as corrugações e as estrias. Fotografei, então, essas superfícies em zoom frontal de forma que as marcas da deterioração e de toda sorte de imperfeição ficassem evidentes. Fotografei em diferentes horas do dia para que a luz, refratada na lente, influenciasse na cor e na tonalidade finais das imagens. Reproduzi cada uma dessas fotografias no formato retangular, nas dimensões $40 \times 30 \mathrm{~cm}$, aproximando-as ao tamanho de um bloco de pedra. O tom terroso, variando do ocre profundo ao cinzento-azulado que cada imagem adquiriu, ajudou-me nesta analogia. 
Pensei o Outro Monumento como a elevação de um plano vertical, massivo, retangular e frontal, maior que o corpo de um homem $(180 \times 240 \mathrm{~cm})$. Deixei que o excesso de massa assentando os blocos emergisse sobre a superfície irregular a fim de salientar o aspecto material do monumento. À frente desta lápide, para acrescentar um pouco de humor nonsense, inseri a fotografia ampliada de um cachorro, um membro daquela matilha de cães que encontrei na primeira visita. Para finalizar, acrescentei dois holofotes laterais no chão que iluminavam a escultura de baixo para cima em reforço ao aspecto cenográfico do monumento e para fazê-lo invadir o espaço tridimensional do espectador. Dessa feita, surgiu um duplo inesperado de uma arquitetura espectral, uma entidade fantasmagórica que, malgrado suas componentes materiais, inscreve-se como imagem no espaço do espectador e avança sobre seu corpo que busca a sombra de um futuro no passado. ${ }^{7}$

Dessa experimentação pioneira, desdobraram-se mais duas formas míticas que se somaram à da lápide ou do colosso apresentada no MAC-Niterói, e vieram a compor a exposição no MunA: a do zigurate e a do pórtico trilítico, conjunto de Monumentos em diálogo enviesado com $\mathrm{O} P e-$ queno gesto.

\section{Como os dois trabalhos se interrelacio- nam na proposta expositiva?}

Tratando-se de trabalhos muito distintos em forma e conteúdo, em procedimentos e conceitos, o pressuposto que os atravessa e os religa, permitindo-nos colocá-los em diálogos em constituição a uma só unidade expositiva, está no par de conceitos opostos e complementares: monumento/antimonumento.

$\mathrm{Se}$, de um lado, as estruturas que recorrem a formas da arquitetura arcaica reforçam a grandiosidade que impressiona o corpo do visitante, instaurando o monumento, por outro lado, as imagens dos gestos diminutos, ao extirpá-los do contexto original das cidades e destacá-los sobremaneira na fotografia, os tornam emblemáticos e grandiloquentes, transformando-os, de certa forma, em monumentos ao derrisório: um antimonumento. 


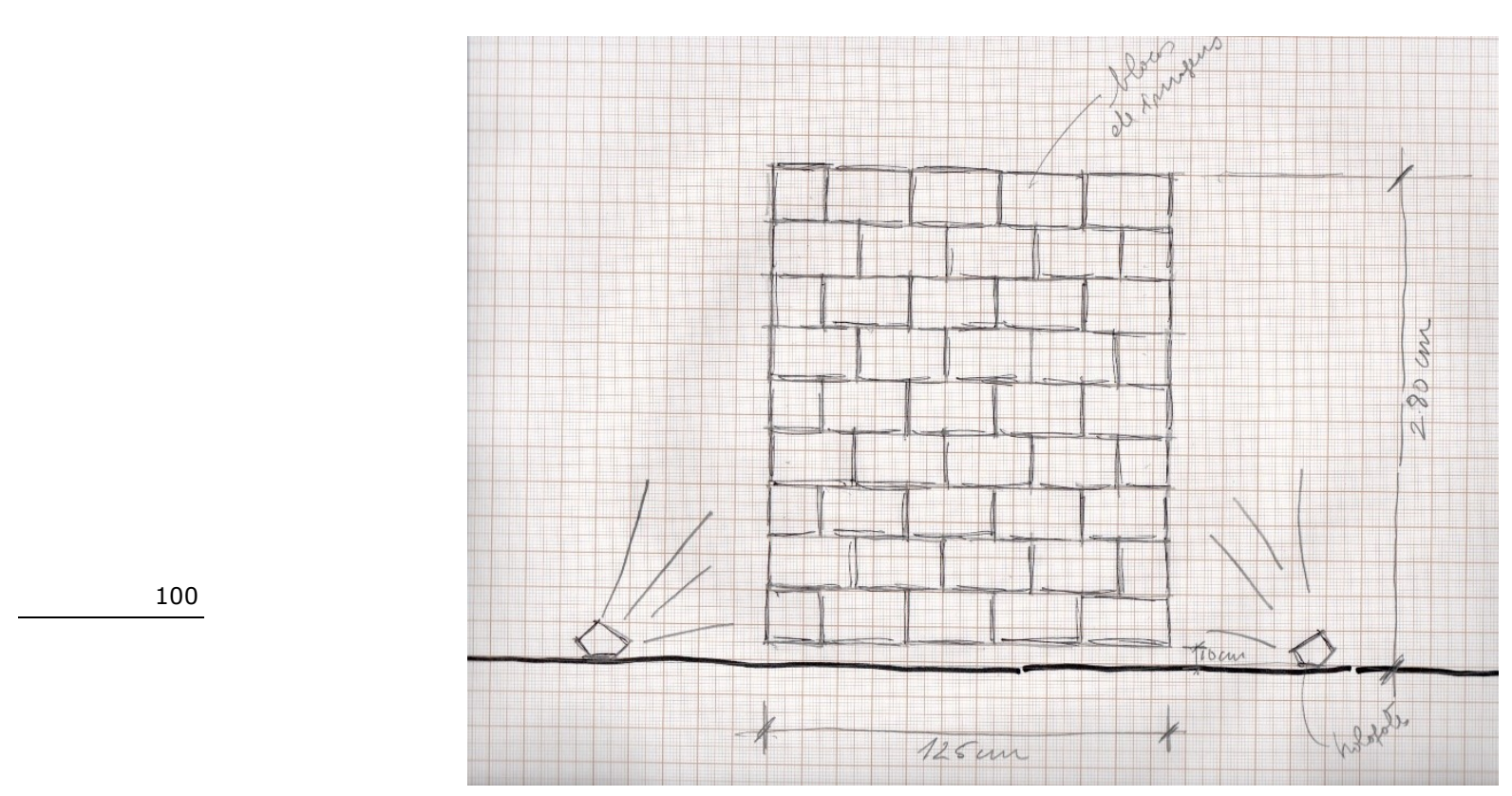




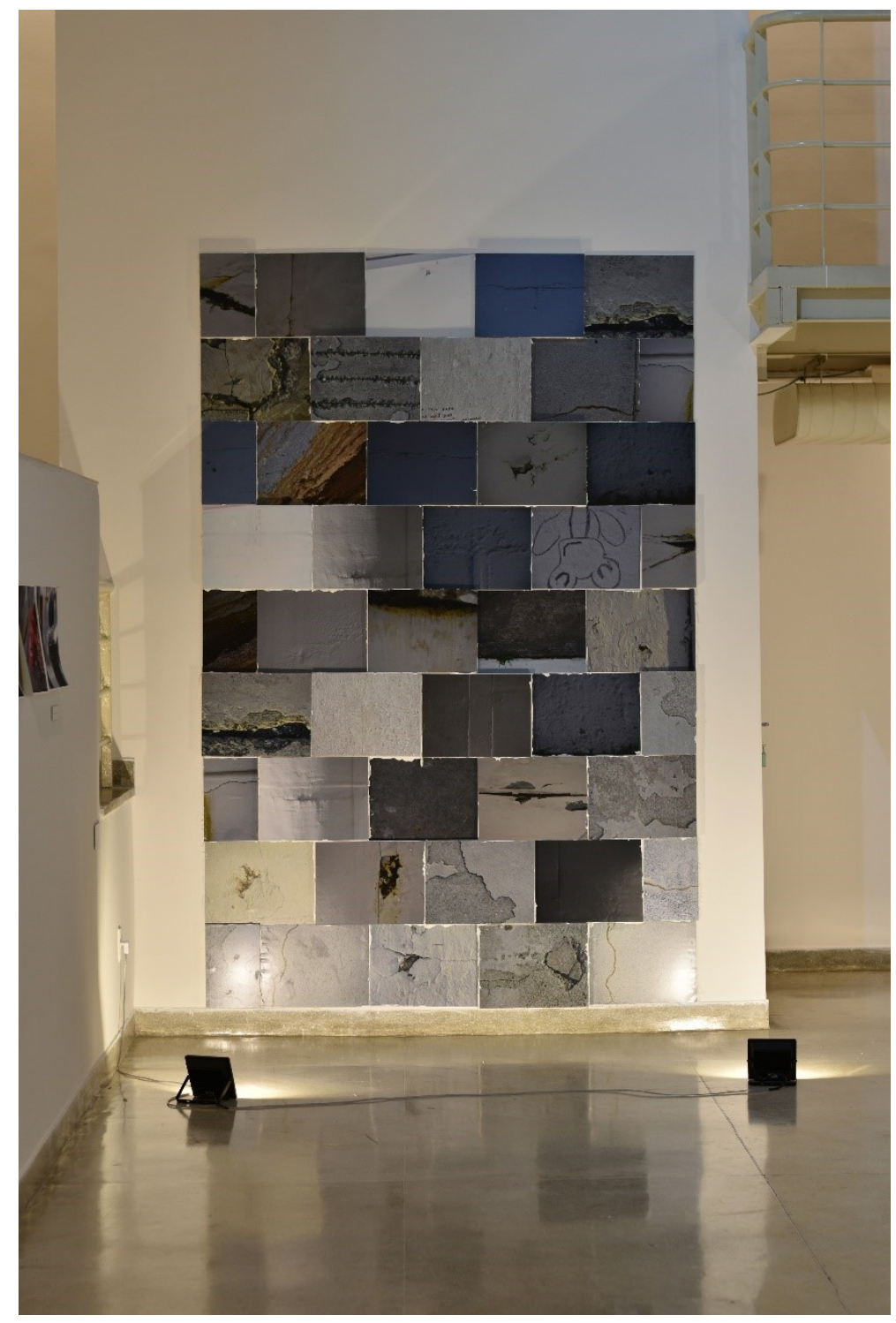




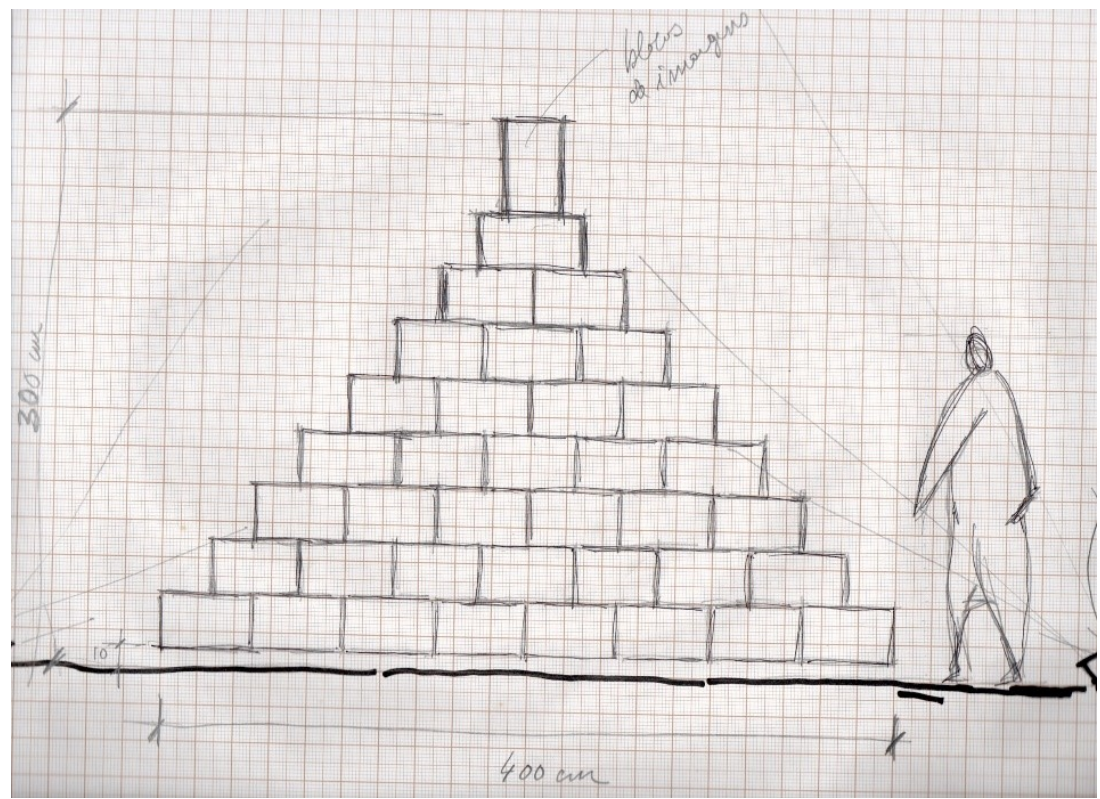

Fig. 11 e 12 (página seguinte) - Luciano Vinhosa, Monumento II (projeto e realização) desenho e fotoqrafia do autor 


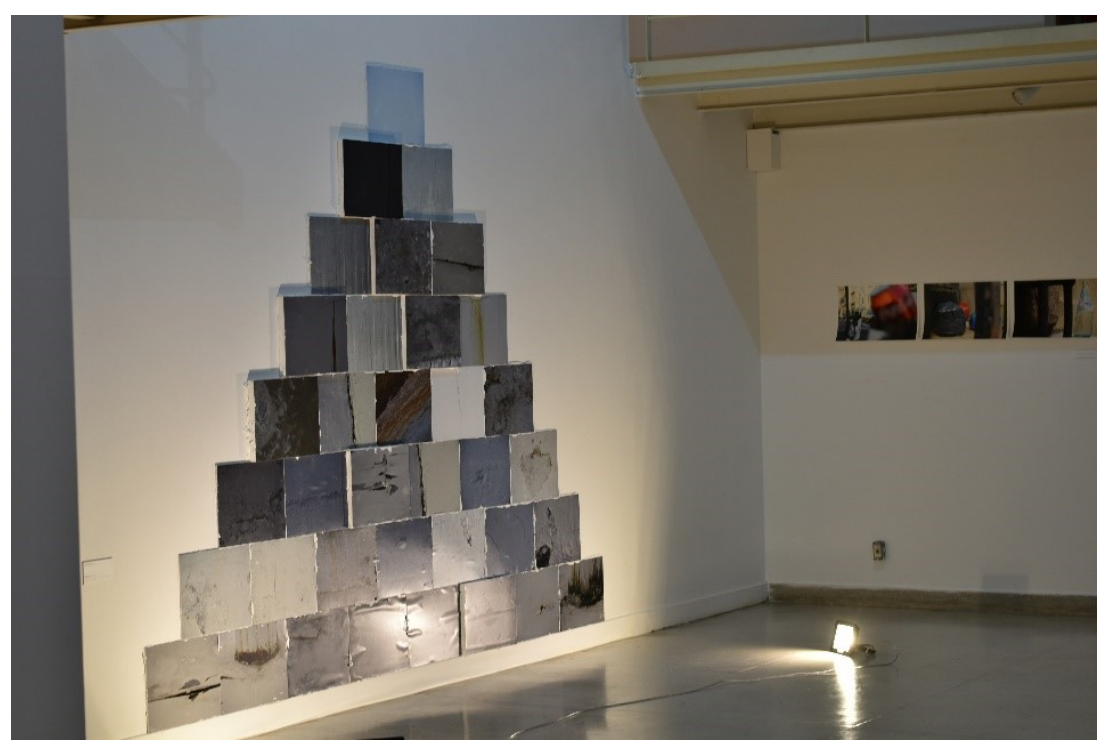



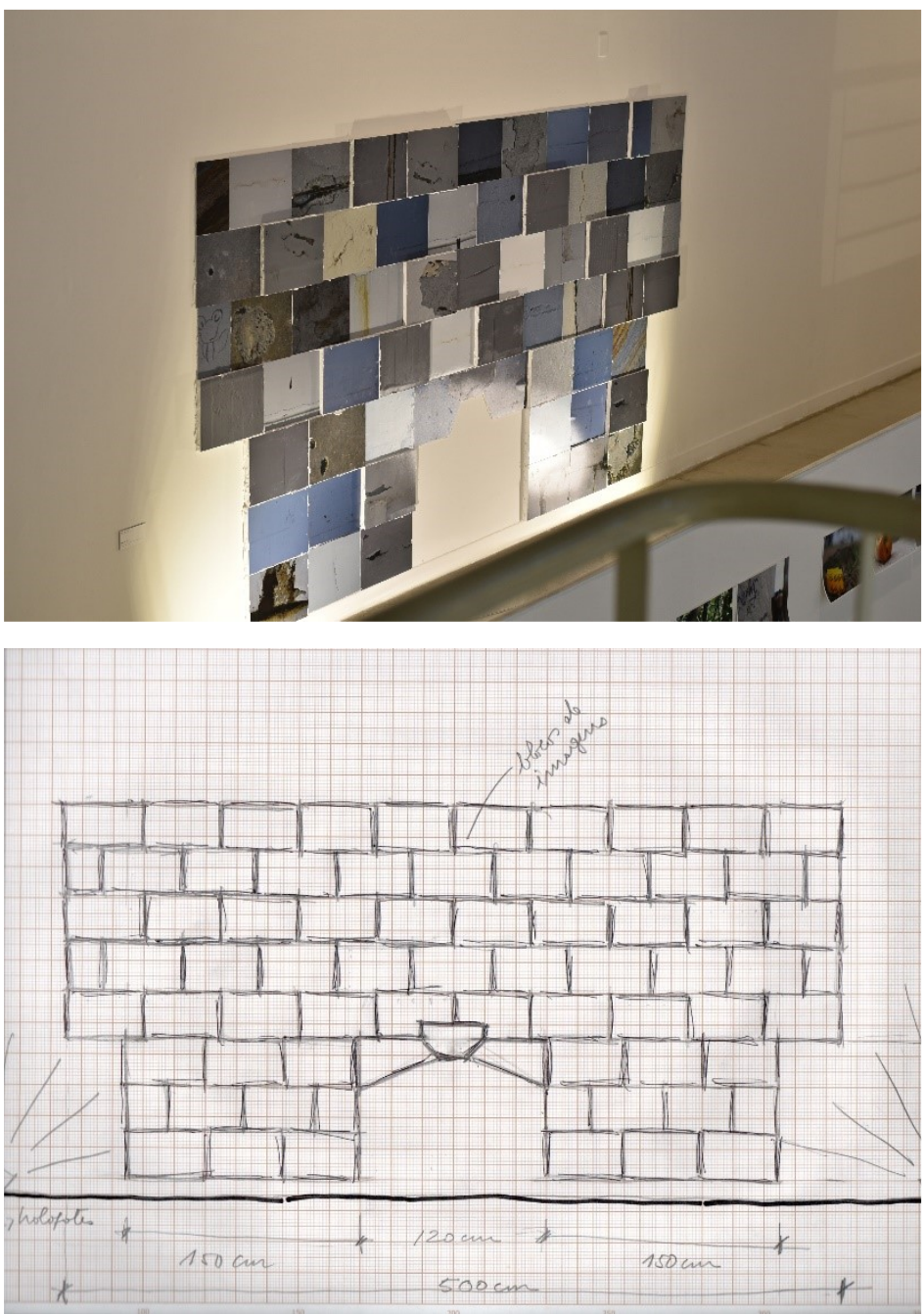

Fig. 13 e 14 - Luciano Vinhosa, Monumento III (projeto e realização) desenho e fotoqrafia do autor 
Uma dupla ironia cruza os trabalhos e costura-os intrinsecamente, ao mesmo tempo em que ela faz relevar do insignificante a significância, do grande no pequeno, do pequeno no grande. Os trabalhos nascem de um espírito crítico e atento à experiência urbana cotidiana sobre a qual me debruço como artista.

\section{Notas}

${ }^{1}$ Esse pressuposto está baseado nas teorias de John Dewey (2006), apresentadas em seu livro Arte como experiência ( $L$ 'art comme expérience), filosofia com a qual Jean-Pierre Cometti estava alinhado.

${ }^{2}$ No original: "Nous percevons les objets qui se trouvent devant nous; mais ce dont nous faisons spécialement l'expérience - la sorte de chose à laquelle le mot expérience s'applique plus particulierment - est un événement. Nous ne percevons pas des événements [...] j'en fais l'expérience plus que je ne le perçois. C'est le champ spécial de l'expérience que nous informe sur les événements, sur les changements de perception. Or, ce qui caractérise en particulier de soudains changements de perception est le choc. [...] le concepte d'expérience est plus large que celui de perception et inclut beaucoup de choses qui ne sont pas, à proprement parler, objets de perception." (Écris sur le signe. Paris: Seuil, 1978, p. 9394).

${ }^{3}$ No original: “Lorsqu'un éclair illumine un paysage sombre, on y reconnaît des objets. Mais cette recon- naissance n'est pas elle-même un simple point dans le temps. Elle est la manifestation, dans un instant culminant, soudain et isolé, de la continuité d'une expérience temporelle ordonnée. Considerée à part, elle est aussi insignifiante que le serait la tragédie d'Hamlet si elle se trouvait limitée à un seul vers ou un seul mot isolé de tout contexte." (L'art comme epérience. Paris: Farago, 2006, p. 45)

${ }^{4} \mathrm{O}$ pequeno gesto tem antecedentes no trabalho que desenvolvi no doutorado, Agenciamentos territoriais, o qual se estrutura como um arquivo fotográfico fundamentado em 15 tipos de território. Sobre esta pesquisa, ver Território: um vento que dá lugar à experiência estética. Arte \& Ensaios, v. 1, n. 16, p. 82-91, 2008.

${ }^{5}$ Sobre esse trabalho, publiquei um ensaio na revista Pós do Programa de Pós-Graduação em Artes da Escola de Belas Artes da UFMG. (Digressões em torno do pequeno gesto. Pós, Revista do Programa de PósGraduação em Artes, UFMG, v. 1, n. 1, p. 106-116, maio 2008. A descrição de todo esse processo também pode ser consultado aqui: https://www.eba. ufmg.br/revistapos/index.php/pos/article/view/257

${ }^{6}$ Iniciativa de organizar um arquivo apareceu-me a partir da leitura do prefácio de As palavras e coisas de Michel Foucault, em que ele menciona um texto de Jorge Luis Borges, no qual o autor se refere a uma enciclopédia chinesa onde estão listados, em ordem alfabética e em estranha classificação, animais fabulosos. (Michel Foucault. As palavras e as coisas. São Paulo: Martins Fontes, 1992)

${ }^{7}$ Uma versão desse texto foi publicada no livro / catálogo Suspended Spaces: a partilha dos esquecidos (Les partage des oublis). Lisboa/Paris: Sistema Solar, 2018. 


\section{Referências}

DEWEY, John. L'art comme epérience. Paris: Farago, 2006.

FOUCAULT, Michel. As palavras e as coisas. São Paulo: Martins Fontes, 1992.

PEIRCE, Charles Sanders. Écris sur le signe. Paris: Seuil, 1978.

SARDO, Delfim. O exercício experimental da liberdade. Lisboa: Orfeu Negro, 2017.

SUSPENDED SPACES (Org.). A partilha dos esquecidos / Les partage des oublis. Lisboa/Paris: Sistema Solar, 2018.

VINHOSA, Luciano. Território: um vento que dá lugar à experiência estética. Arte \& Ensaios, UFRJ, v. 1, n. 16, p. 82-91, 2008.

VINHOSA, Luciano. Notas digressivas em torno do pequeno gesto. Pós, Revista do Programa de Pós-Graduação em Artes (UFMG), v. 1 , n. 1 , p. 106-116, maio 2008. 